\title{
Catalytic Hydrolysis of Ethyl Acetate using Cation Exchange Resin (Amberlyst - 15) : A Kinetic Study
}

\author{
K.R. Ayyappan, Amrit Pal Toor, Ritu Gupta, Ajay Bansal, and \\ R.K. Wanchoo*
}
Department of Chemical Engineering \& Technology Panjab University, Chandigarh-160014, INDIA

Received: 19 July 2009; Revised: 20 August 2009; Accepted: 22 August 2009

\begin{abstract}
The kinetic behavior of the heterogeneous hydrolysis of aqueous ethyl acetate over an acidic cation exchange resin, Amberlyst 15, was investigated. The experiments were carried out in a fixed bed reactor at temperatures from 313.15 to $343.15 \mathrm{~K}$ and feed molar ratios , $\theta_{\text {во }}$ (water to ethyl acetate) from 62.4 to 265.88. The conversion of ethyl acetate was found to increase with increasing reaction temperature. Gas bubble formation was observed at reaction temperature $\geq 343.15 \mathrm{~K}$. Absence of mass transfer resistance was verified by conducting the experiments at different catalyst loadings $(20 \mathrm{~g}, 40 \mathrm{~g}, 64 \mathrm{~g})$ under varied feed flow rates ( 1 to $25 \mathrm{~cm}^{3} / \mathrm{min}$ ). The kinetic data was correlated with pseudo first order model and model parameters were determined using Nelder-Mead algorithm for minimizing the objective function. (C) 2009 BCREC. All rights reserved.
\end{abstract}

Keywords: Hydrolysis, Ethyl acetate, Amberlyst-15, Kinetics

\section{Introduction}

Liquid phase hydrolysis and esterification in which water exists as one of the reactants or products are usually catalyzed by homogenous acids such as $\mathrm{H}_{2} \mathrm{SO}_{4}$. Sulphuric acid being a homogenous acid poses problems due to corrosion, disposal, and handling. Alternatively, the use of heterogeneous catalyst like Niobic acid [1], ion exchange resin [2,3] and metal oxides [1] have been reported to have overcome these problems. However, catalyst like Niobic acid and metal oxides needs special treatment and performance of these catalysts is sensitive to the pretreatment conditions [1]. Hence, ion-exchange resins are preferred over homogenous acids due to ease of product separation and catalyst recovery. Apart from their prominence in separation and purification of products, ion exchange resins have been used as catalyst for esterification/hydrolysis reactions [2,3], phenol alkylation and hydration of olefins [4].

The reaction kinetics and chemical equilibrium of the reversible esterification of methanol with acetic acid were investigated by Popken et al. [5], and Han et al.[6]. The reaction was catalyzed both homogeneously by acetic acid itself and heterogeneously by an acidic ion-exchange resin (Amberlyst-15). New phenomenon of in-situ coating by the reactant/product on ion exchange

\footnotetext{
* Author for Correspondence, E.Mail: wanchoo@pu.ac.in
} 
resin catalyst, Amberlyst-15, that helps to improve the reaction kinetics of dicyclopentadiene (DCPD) hydration has been reported by Talwalkar et al. [7]. The aza-Michael reactions of amines with unsaturated carbonyl and nitrile compounds have efficiently been carried out at room temperature using Amberlyst-15 as a heterogeneous reusable catalyst. The products were formed in short reaction times and in high yields [8]. The catalyst Amberlyst-15, is commercially available, inexpensive and nonhazardous. It works under heterogenous conditions, can easily be handled and removed by simple filtration [8]. There is growing research using amberlyst-15 catalyst for esterification reactions [5,9-11] but not much work is reported on hydrolysis reaction.

Recovery of ethyl acetate from dilute aqueous process waste streams commonly found in the specialty chemicals and pharmaceutical industry may be handled by pervaporation or hydrolysis. In case of hydrolysis, recovered acetic acid can be reused in the process.

The aim of the present study was to investigate the applicability of the macro porous cation exchange resin (Amberlyst 15 in acid form) for the hydrolysis reaction and to examine the effects of flow rate, temperature, and catalyst loading on the reaction rate.

\section{Materials and Methods \\ 2.1. Materials used}

Reagent grade Ethyl Acetate (98\%) from Qualigens Fine chemicals Ltd and double distilled water have been used in all the experimental runs. Amberlyst-15 supplied by Rohm and Haas was used as catalyst and its relevant characteristics are summarized in Table 1.

\subsection{Experimental Setup}

The fluid solid catalytic reaction was carried out in a continuous flow laboratory scale packed bed reactor at atmospheric pressure (Figure 1). A double walled Borosil glass tube (length $70 \mathrm{~cm}$, outer diameter $4.4 \mathrm{~cm}$, inner diameter $2.2 \mathrm{~cm}$ ) was maintained at constant temperature by circulating water from the constant temperature bath (Julabo F30) through the annulus of the reactor. The temperature was controlled to within \pm 0.1 ${ }^{\circ} \mathrm{C}$. A known amount of fresh/regenerated catalyst in acid form was packed into the reactor supported on a stainless steel mesh. A simple pre-
Table 1. Physicochemical properties of Amberlyst-15

\begin{tabular}{|l|l|}
\hline Skeleton & $\begin{array}{l}\text { Styrene -Divinyl ben- } \\
\text { zene }\end{array}$ \\
\hline Type & strong acid \\
\hline Structure & macro reticular \\
\hline Functional group & sulfonic $\left(\mathrm{SO}_{3} \mathrm{H}\right)$ \\
\hline Ionic form & Hydrogen \\
\hline Cross- linking degree & $20 \%$ \\
\hline Particle size & $0.35-1.2 \mathrm{~mm}$ \\
\hline Internal porosity & 0.36 \\
\hline $\begin{array}{l}\text { Concentration of acid } \\
\text { sites }\end{array}$ & $\begin{array}{l}4.53 \mathrm{~m}_{\text {equiv }} \mathrm{g}^{-1} \text {. of dry } \\
\text { resin }\end{array}$ \\
\hline Bulk density & $600 \mathrm{~kg} \mathrm{~m}^{-3}$ \\
\hline Polymer density & $1410 \mathrm{~kg} \mathrm{~m}^{-3}$ \\
\hline
\end{tabular}

treatment was used to convert the catalyst into acid form. At first catalyst was washed with distilled water three to four times and dried at atmospheric conditions. The dried catalyst was soaked in $0.1 \mathrm{~N}$ hydrochloric acid solution for half an hour. Thereafter the catalyst was separated and dried at ambient conditions for $48 \mathrm{hrs}$.

\subsection{Procedure}

The aqueous ethyl acetate solution from the feed tank was first heated to the desired reaction temperature by passing it through a coiled heat exchanger. The feed solution was uniformly dispersed on the top surface of the catalyst bed at the desired flow rate using valve FC (Figure 1). The volumetric flow rate of the feed was periodically calibrated with pure water. The reaction temperature was regulated to within $\pm 0.1^{\circ} \mathrm{C}$ by circulating thermostatic water through the reactor jacket. A precision digital thermometer measured the reactant temperature to an accuracy of \pm $0.01^{\circ} \mathrm{C}$. Once a steady state was attained, the product was collected in a sampling flask. The amount of acetic acid in the sample was analyzed with $0.1 \mathrm{~N}$ standard solution of $\mathrm{NaOH}$. At least five replicated samples were taken under each of the experimental conditions and reproducibility was within $\pm 2 \%$. The conversion of ethyl acetate was calculated from the stoichiometry of the reaction. A complete conversion curve was obtained by conducting the experiment with various flow rates. Each set of experiment was carried out using fresh/regenerated catalyst. Experimental runs were carried out at different feed flow rate, reaction temperature, feed solution concentration and 


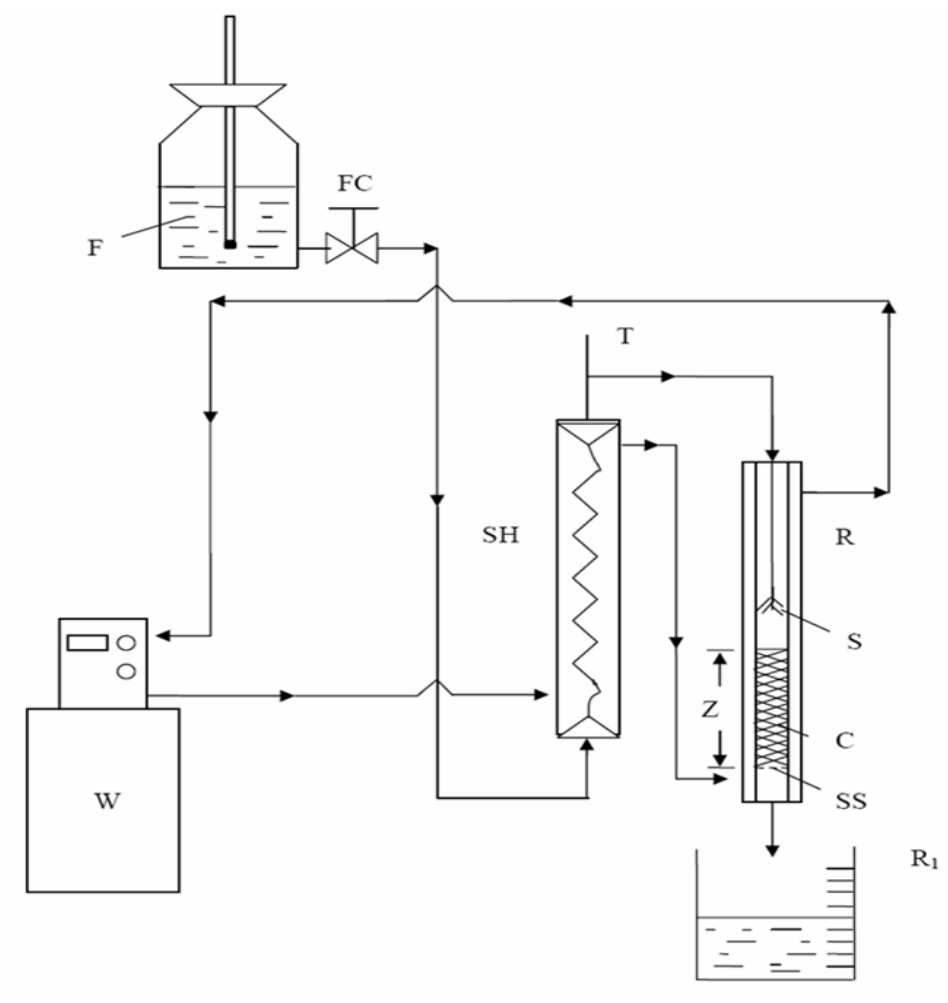

F -Aqueous Ethyl Acetate Feed Tank, FC - Flow Controller, W - Constant Temperature Water Bath , T Mercury Thermometer, SS - Stainless Steel Sieve, S - Sprayer, R - Packed Bed Reactor, SH - Spiral Heat Exchanger , C - Catalyst Bed , $R_{1}$ Receiver , Z - Height of the Catalyst Bed

Figure 1. Experimental setup

catalyst loading. For each run, only one parameter was varied at a time.

\section{Results and Discussion}

The kinetics of hydrolysis of ethyl acetate was studied at temperatures from 313.15 to $343.15 \mathrm{~K}$ with four different molar feed ratios $\left(\theta_{\text {Во }}\right.$ $=265.88,130.226,85.115,62.4$, where $\theta_{\text {во }}$ is the molar ratio of water to ethyl acetate ). All the experiments were carried out with various volumetric flow rates of feed (F) at fixed conditions of reaction temperature and feed composition. The contact time $(\tau)$ of the reactants with catalyst is defined as :

$$
\tau=\mathrm{W} / \mathrm{F}
$$

A wide range of volumetric flow rates of the feed was covered in the experiments for which conversion of ethyl acetate $\left(\mathrm{X}_{\mathrm{A}}\right)$ varied from 0.112 to 0.877 . Results of the hydrolysis measurement are tabulated in Table 2. Figure 2 presents the variation of $\mathrm{X}_{\mathrm{A}}$ with contact time for the hydrolysis reaction taking place at $\theta_{\mathrm{BO}}=265.88, \mathrm{~W}=64 \mathrm{~g}$, over a temperature range of 313.15 to $343.15 \mathrm{~K}$. It shows that the conversion of ethyl acetate increases with increase in reaction temperature. Figure 3 illustrates the variation in conversion with contact time at $323 \mathrm{~K}$ under different feed compositions. At a given contact time, greater conversions are achieved at higher $\theta_{\mathrm{Bo}}$.

By visual inspection, gas bubbles were formed at temperature greater then $343.15 \mathrm{~K}$. To investigate the influence of the transport resistance by film diffusion or pore diffusion, experiments were also carried at different catalyst loadings ( $20 \mathrm{~g}, 40$ g, $64 \mathrm{~g})$. Figure 4 compares the results at 323.15 $\mathrm{K}$ and $\theta_{\mathrm{BO}}=265.88$ with different catalyst loading 
Table 2. Range of experimental parameters observed during hydrolysis of aqueous ethyl acetate using Amberlyst- 15 as catalyst

\begin{tabular}{|c|c|c|c|c|c|c|}
\hline S. No. & $\begin{array}{l}\text { Reaction } \\
\text { Temp., T, } \\
\text { K }\end{array}$ & $\begin{array}{l}\text { Molar } \\
\text { feed } \\
\text { Ratio, } \\
\theta_{\text {Bo }}\end{array}$ & $\begin{array}{l}\text { Catalyst } \\
\text { Weight, } \\
\text { W, g }\end{array}$ & $\begin{array}{l}\text { Feed Conc., } \mathrm{C}_{\mathrm{Ao}} \text {, } \\
10^{-3} \mathrm{~mol} \mathrm{~cm}^{-3}\end{array}$ & $\begin{array}{l}\text { Range of Contact } \\
\text { Time , } \tau, \mathrm{g} \text { min } \mathrm{cm}^{-3}\end{array}$ & $\begin{array}{l}\text { Range of } \\
\text { conversion, } \\
\mathrm{X}_{\mathrm{A}}\end{array}$ \\
\hline 1 & 313.15 & 265.88 & 64 & 0.205 & $3.333-16.671$ & $0.130-0.492$ \\
\hline 2 & 323.15 & 265.88 & 64 & 0.205 & $3.152-16.671$ & $0.199-0.657$ \\
\hline 3 & 333.15 & 265.88 & 64 & 0.205 & $2.958-16.954$ & $0.275-0.819$ \\
\hline 4 & 343.15 & 265.88 & 64 & 0.205 & $3.133-13.333$ & $0.385-0.877$ \\
\hline 5 & 313.15 & 130.23 & 64 & 0.410 & $3.125-16.671$ & $0.115-0.450$ \\
\hline 6 & 323.15 & 130.23 & 64 & 0.410 & $3.333-16.671$ & $0.195-0.601$ \\
\hline 7 & 333.15 & 130.23 & 64 & 0.410 & $2.985-16.628$ & $0.261-0.760$ \\
\hline 8 & 343.15 & 130.23 & 64 & 0.410 & $3.333-13.333$ & $0.378-0.812$ \\
\hline 9 & 313.15 & 85.12 & 64 & 0.614 & $3.333-16.667$ & $0.112-0.418$ \\
\hline 10 & 323.15 & 85.12 & 64 & 0.614 & $3.333-14.267$ & $0.112-0.377$ \\
\hline 11 & 333.15 & 85.12 & 64 & 0.614 & $3.333-16.667$ & $0.263-0.701$ \\
\hline 12 & 343.15 & 85.12 & 64 & 0.614 & $2.958-13.333$ & $0.318-0.760$ \\
\hline 13 & 313.15 & 62.40 & 64 & 0.820 & $3.333-16.667$ & $0.109-0.385$ \\
\hline 14 & 323.15 & 62.40 & 64 & 0.820 & $3.125-16.728$ & $0.156-0.536$ \\
\hline 15 & 333.15 & 62.40 & 64 & 0.820 & $3.136-16.667$ & $0.236-0.659$ \\
\hline 16 & 323.15 & 265.88 & 64 & 0.205 & $3.152-16.671$ & $0.199-0.658$ \\
\hline 17 & 323.15 & 265.88 & 40 & 0.205 & $2.139-17.778$ & $0.124-0.587$ \\
\hline 18 & 323.15 & 265.88 & 20 & 0.205 & $1.053-12.121$ & $0.066-0.525$ \\
\hline
\end{tabular}

indicating that all experimental points fall on the same curve. Thus the effect of film and pore diffusion appear to be negligible at present experimental conditions [3,13]. Figure 5 illustrates the effect of flow rate on conversion $\left(\mathrm{X}_{\mathrm{A}}\right)$ at $313 \mathrm{~K}$ at $\theta_{\mathrm{Bo}}=$ 265.88. Experiments were carried out using volumetric feed flow rates (F) in the range of 1 to 20 $\mathrm{cm}^{3} / \mathrm{min}$ at different molar feed ratios $\theta_{\text {Bo. From }}$ Figure 5 it is observed that as flow rate increases conversion of ethyl acetate decreases.

\section{Correlation of kinetic data :}

The kinetic data were correlated with mass balance equation for ethyl acetate around the entire packed bed reactor by:

$$
\left(\frac{W}{F C_{A O}}\right)=\int_{0}^{X A} \frac{d X{ }_{A}}{-r_{A}}
$$

The rate expression for $-r_{A}$ depends on the assumption of the reaction mechanism. The basic reaction stoichiometry involved in hydrolysis of ethyl acetate is :

$$
\begin{aligned}
\mathrm{CH}_{3} \mathrm{COOC}_{2} \mathrm{H}_{5}(\mathrm{~A})+\mathrm{H}_{2} \mathrm{O}(\mathrm{B}) \leftrightarrow \leftrightarrow & \mathrm{CH}_{3} \mathrm{COOH}(\mathrm{C}) \\
& +\mathrm{C}_{2} \mathrm{H}_{5} \mathrm{OH} \text { (D) }
\end{aligned}
$$

In the present study, the initial concentration of ethyl acetate $\left(\mathrm{C}_{\mathrm{Ao}}\right)$ was varied from 2 to $8 \%(\mathrm{v} /$ v). Since, water being in large excess, a pseudo first order irreversible kinetic model was assumed to represent the data. The rate equation $\left(-r_{A}\right)$ for the pseudo-first order formalism is :

$$
-r_{A}=\left(k_{1} C_{B O}\right) C_{A} \text { or }-r_{A}=k C_{A} \quad 3
$$

Where $\mathrm{k}$ is the pseudo first order rate constant based on the weight of the catalyst. Integration of Equation (2) with pseudo first order reaction rate, - $\mathrm{r}_{\mathrm{A}},(\mathrm{Eq},(3))$ yields:

$$
\left(\frac{W}{F C_{A O}}\right)=\frac{\ln \left(\frac{1}{\left(1-X_{A}\right)}\right)}{k_{o} \exp \left(-\frac{E_{0}}{R T}\right) \theta_{B O} C_{A C}^{2}}
$$

where,

$$
\theta_{B O}=\left(\frac{C_{B O}}{C_{A O}}\right) \quad k=k_{0} \exp \left(\frac{-E_{0}}{R T}\right)
$$




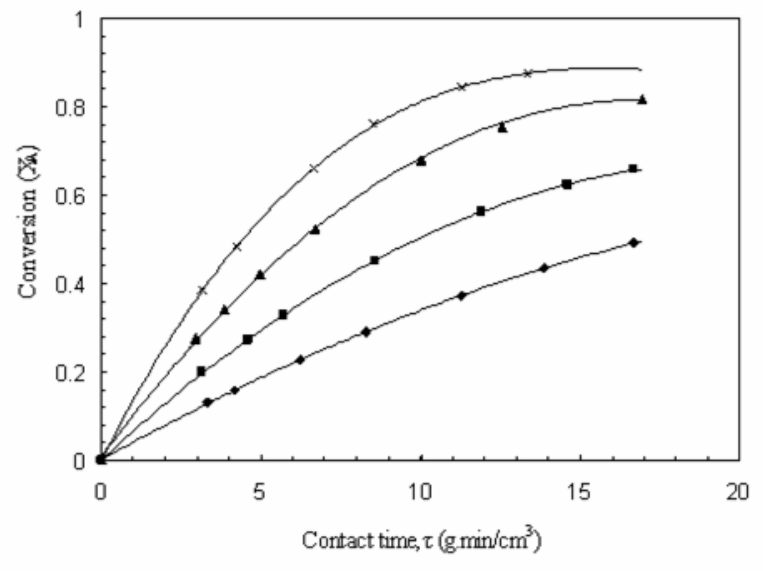

Figure 2. Conversion vs Contact time for $\theta_{\mathrm{BO}}=$ 265.88, W= $64 \mathrm{~g}$; at different temperatures, $\mathrm{T}$ : $(\diamond)$ $313.15 \mathrm{~K},(\mathbf{\bullet}) 323.15 \mathrm{~K},(\boldsymbol{\Delta}) 333.15 \mathrm{~K},(\mathrm{x}) 343.15 \mathrm{~K}$.

The kinetic data was fitted to Equation (4) using least square regression technique (Nelder Mead algorithm) and the model parameters, $\mathrm{E}_{0}$ and $\mathrm{k}_{\mathrm{o}}$ were evaluated. The total number of data points used in parameter estimation were 108. The results of the data correlation yielded the following:

- Activation EnergyE $E_{0}=41140 \mathrm{~J} / \mathrm{mole}^{-1}$

- Arrhenius pre-exponential factor $\mathrm{k}_{0}=5.247$ $\mathrm{x} 10^{6} \mathrm{~cm}^{6} \mathrm{~g}^{-1} \mathrm{~mole}^{-1} \mathrm{~min}^{-1}$

- a correlation coefficient $\mathrm{R}^{2}=0.99$.

Using these model parameters, parity between $\left(\frac{W}{F C_{A O}}\right)$ experimenta the values based on pseudo first order kinetic model ( Equation (4)) is shown in Figure 6. The model explains the present experimental data to within $\pm 10 \%$ with MRQE value of 0.033 . Based on pseudo first order model, rate constant,

$$
k=\frac{F}{W \theta_{B o} C_{A o}} \ln \left(\frac{1}{1-X_{A}}\right)
$$

at various temperatures were obtained at different feed concentration and are tabulated in Table 3. From this table, constant values of rate constant are observed, within the accuracy of experimental data; for different feed concentrations at all temperatures.

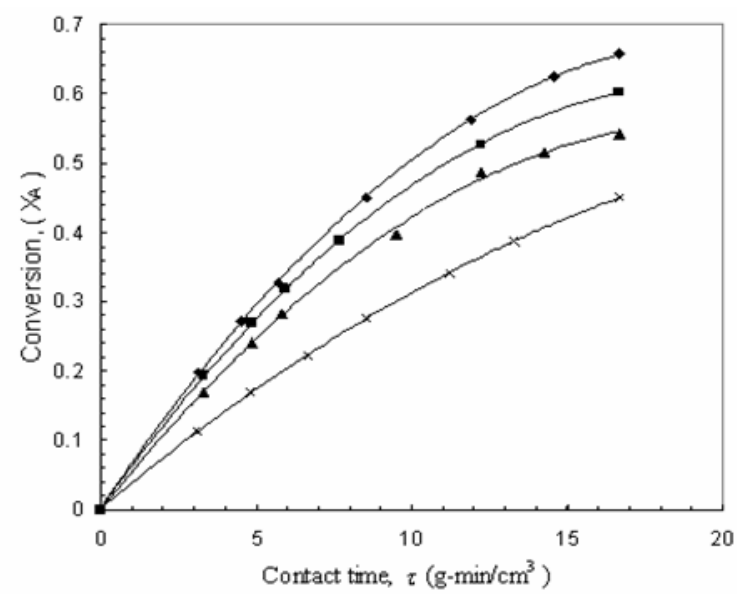

Figure 3. Conversion vs Contact time forW $=64 \mathrm{~g}$, $\mathrm{T}=323.15 \mathrm{~K}$; for different feed ratios, $\theta_{\mathrm{BO}}:(\bullet)$ 265.88, (ロ)130.226, (ム)85.115, (x) 62.4

\section{Conclusions}

The kinetic behavior of the hydrolysis of ethyl acetate in presence of large excess of water over Amberlyst-15 (in acid form) has been studied experimentally over reaction temperature from 313.15 to $343.15 \mathrm{~K}$ and molar ratios of feed $\left(\theta_{\mathrm{Bo}}\right)$ from 62.4 to 265.88 . Under the investigated conditions, the absence of mass transfer resistance was verified experimentally. Pseudo first order kinetic model has been applied to correlate the kinetic data of the liquid solid reaction. The hydrolysis reaction is well represented by:

$$
-r_{A}=5.247 \times 10^{6} \exp (-41140 / R T) \theta_{B O} C_{A O}^{2}\left(1-X_{A}\right)
$$

\section{REFERENCES}

1. Okazaki, S., Harada, H.,1988, Vapor-phase Hydration of Dicyclopentadiene Catalyzed by Niobic Acid, Chem. Lett., 8: 1313-1316.

2. Yadav, G.D., Mehta, P.H., 1994, Hetrogenous Catalysis in Esterfication Reactions: Preparation of Phenethyl Acetate and Cyclohexyl Acetate by Using a Variety of Solid Acidic Catalysts, Ind. Eng. Chem. Res., 33 (9): 2198-2208.

3. Yadav, G.D., Thathagar, M.B., 2002, Esterfication of Maleic acid with Ethanol 


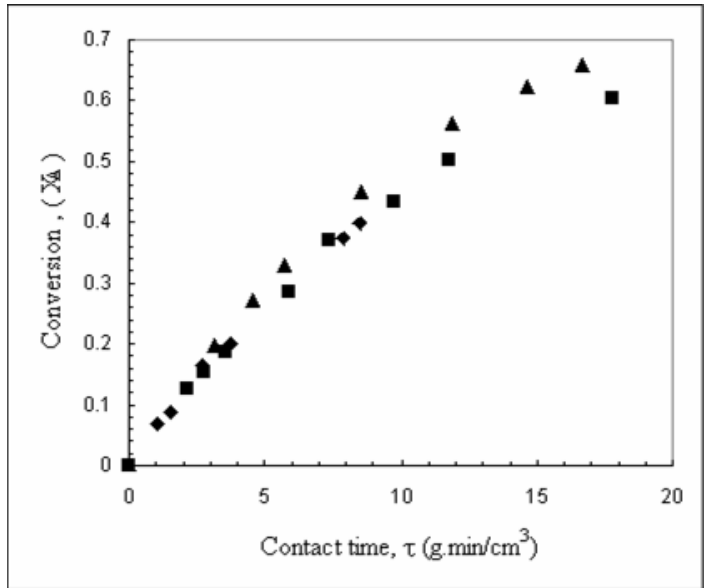

Figure 4. Conversion of ethyl acetate under different catalyst loading at $323.15 \mathrm{~K}$ and $\theta_{\mathrm{BO}}=$ 265.88: (•) $20 \mathrm{~g},(\mathbf{\bullet}) 40 \mathrm{~g},(\mathbf{\Lambda}) 64 \mathrm{~g}$.

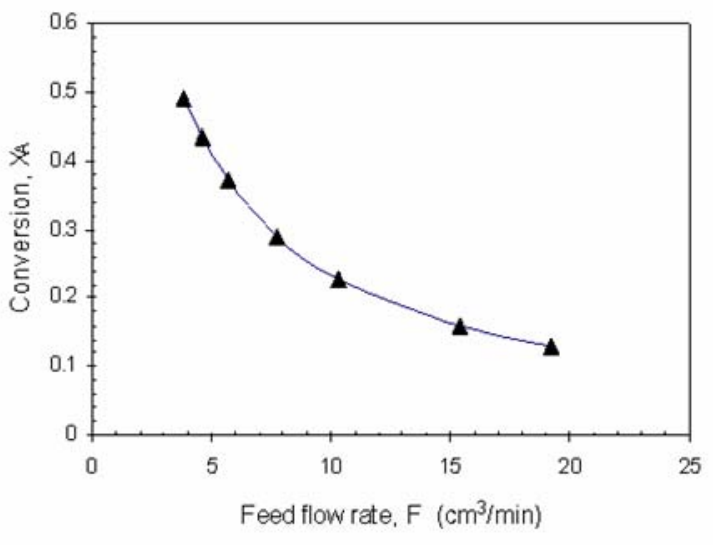

Figure 5. Conversion of ethyl acetate under different feed flow rates at $313.15 \mathrm{~K}$ and $\theta_{\mathrm{Bo}}=265.88$

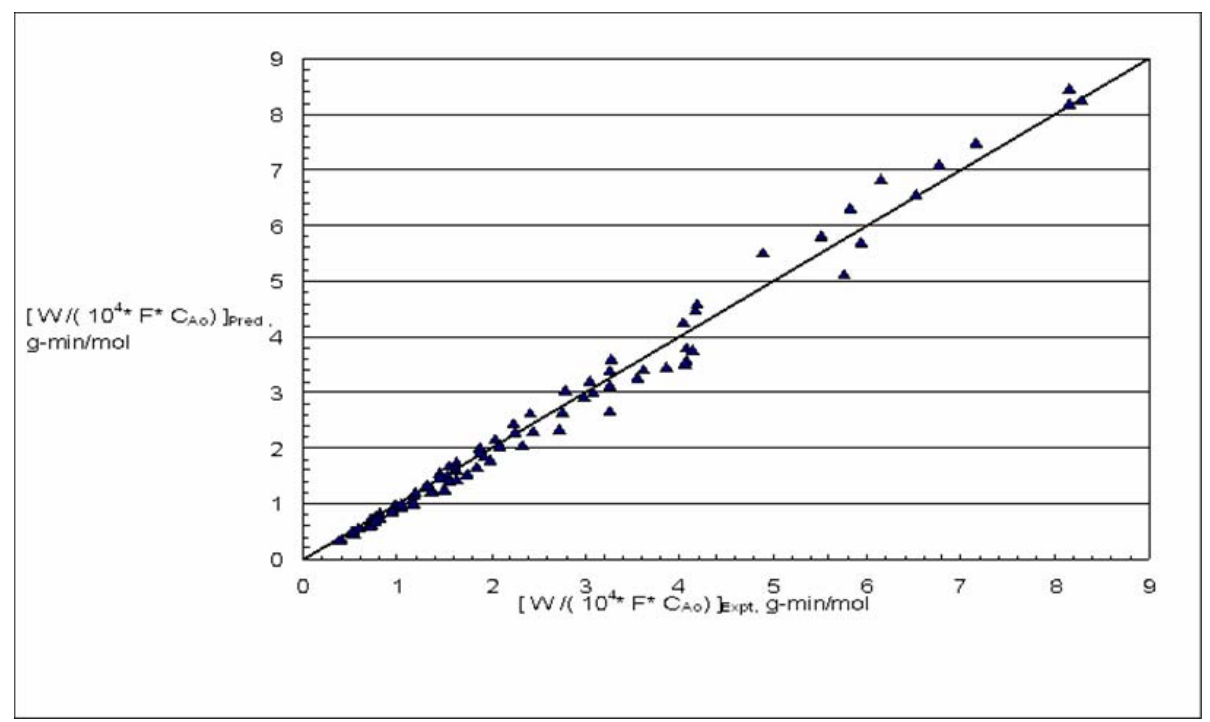

Figure 6 . Parity between observed and predicted values of $\left(\frac{W}{F C_{A O}}\right)$

Table 3. Values of rate constant $\mathrm{k}$, at different reaction temperatures, for various initial feed concentra tions.

\begin{tabular}{|c|c|c|c|c|}
\hline \multirow[b]{2}{*}{$\begin{array}{c}\text { Temperature } \\
(\mathrm{K})\end{array}$} & \multicolumn{4}{|c|}{ Observed Rate Constant, $\mathrm{k}, \mathrm{cm}^{6} \mathrm{~g}^{-1} \mathrm{~mol}^{-1} \mathrm{~min}^{-1}$} \\
\hline & $2 \%$ Feed & $4 \%$ Feed & $6 \%$ Feed & $8 \%$ Feed \\
\hline 313.15 & 0.760 & 0.705 & 0.652 & 0.634 \\
\hline 323.15 & 1.262 & 1.170 & 1.085 & 0.999 \\
\hline 333.15 & 2.013 & 1.825 & 1.639 & 1.525 \\
\hline 343.15 & 2.948 & 2.719 & 2.343 & (Bubble formation) \\
\hline
\end{tabular}


Over Cation Exchange Resin Catalysts, React. Funct. Polym. 52: 99-110.

4. Ueda, N., Matsuba, K., Ikeda, K., Inoue, K., Yamamoto, S., Io, H., 1999, JP 11076830

5. Popken, T., Gotze, L., Gmehling, J., 2000, Reaction Kinetics and Chemical Equilibrium of Homogenously and Heterogeneously Catalysed Acetic acid Esterfication with Methanol and Methyl Acetate Hydrolysis, Ind. Eng. Chem. Res., 39: 2601-2611.

6. Han, S.J., Jin, Y., Yu, Z.Q., 1997, Application of Fluidized Reaction-Distillation Column for Hydrolysis of Methyl Acetate, Chem. Eng. J., $66: 227-230$.

7. Talwalkar, S., Kumbhar, P., Mahajani, S., 2006, In Situ Coating on Cation Exchange Resin Catalyst, Amberlyst-15, and its Impact on the Hydration of Dicyclopentadiene, Catalysis Communications, 7 : 717-720.

8. Das, B., Chowdhury, N., 2007, An Efficient Reusable Heterogeneous Catalyst for azoMichael Reactions Under Solvent Free Condition, Journal of Molecular Catalysis A: Chemical, $263: 212-215$

9. Dassy, S., Wiame, H., Thyrion, F., 1994, Kinetics of the Liquid Phase Synthesis and Hydrolysis of Butyl Lactate Catalysed by Cation Exchange Resin, $J$ Chem Tech Biotechnol., 59: 149-156.

10. Lee, M., Wu, H.T., Lin, H., 2000, Kinetics of Catalytic Esterfication of Acetic Acid and Amyl Alcohol over Dowex, Ind. Eng. Chem. Res., 39 : 4094 -4099.

11. Mazzotti, M., Neri, B., Gelosa, D., Kruglov, A., Morbidelli, M., 1997, Kinetics of Liquid Phase Esterfication Catalysed by Acidic Resin, Ind. Eng. Chem. Res., 36: 3-10.

12. Yadav, G.D., Kulkarni, H.B., React. 2000, Ion Exchange Resin Catalysis in the Synthesis of Isopropyl Lactate, Funct. Polym. 44 (2) : 153165.

\section{Nomenclature}

$$
\begin{aligned}
& \text { A Ethyl acetate } \\
& \text { B Water } \\
& \text { C Acetic acid } \\
& \mathrm{C}_{\mathrm{Ao}} \quad \text { Inlet concentration of ethyl acetate, mol } \\
& \mathrm{Cm}^{-3}
\end{aligned}
$$

MRQE Mean relative quadratic error

$$
=\sqrt{\frac{\sum\left(\frac{\text { exp }- \text { pred }}{\exp }\right)^{2}}{N-1}}
$$

where $\mathrm{N}$ is total number of data points

$\mathrm{R} \quad$ Gas law constant, $\mathrm{J} \mathrm{mol}^{-1} \mathrm{~K}^{-1}$

$\mathrm{R}^{2} \quad$ Correlation coefficient

$-r_{A}$ Rate of reaction,

$\mathrm{T} \quad$ Reaction Temperature, $\mathrm{K}$

W Catalyst loading, $\mathrm{g}$

$\mathrm{X}_{\mathrm{A}} \quad$ Fractional conversion of ethyl acetate

$\theta_{\text {Bo }} \quad$ Molar ratio of the feed (water to ethyl acetate)

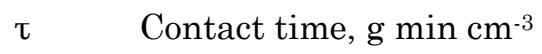

